AROUEOLOGÍA Y SOCIEDAD

№ $26,2013: 395-406$

ISSN: 0254-8062

RECIBIDO: 30 / MAR. / 2013

ACEPTADO: 20 / MAY. / 2013

\title{
EL LARGO CAMINO A LA MUERTE: APUNTES SOBRE TRATAMIENTOS PREY POSTDEPOSICIONALES DE CADÁVERES EN CEMENTERIOS CONTEMPORÁNEOS EN EL PERÚ
}

\author{
Flavio Estrada MORENO \\ Instituto de Medicina Legal y Ciencias Forenses del Ministerio Publico \\ flavio_estrada@hotmail.com
}

\section{RESUMEN}

Se presenta una serie de apuntes de campo realizados durante las labores de recuperación de restos humanos y elementos asociados de personas muertas en su mayoría durante los años 80 al 2000 en diversos cementerios del Perú.

Palabras Clave: Cementerios, prácticas funerarias, muerte, arqueología funeraria, arqueología de la muerte.

\section{AbSTRACT}

We present a series of field notes made during the recovery efforts of human remains and associated elements of people killed mostly during the 80 s to 2000 in various cemeteries of Peru.

KEYwords: Cemeteries, funeral practices, death, burial archeology, archeology of death.

Alli todos están muertos... jtodos están muertos...j Demente en las rejas de la Morgue Central de Lima.

Un día de diciembre de 2012

\section{INTRODUCCIÓN}

Durante los años que duro la violencia interna en el Perú un número aproximado de entre 15,000 a 16,000 peruanos murieron. Ellos llevados por sus familiares y amigos fueron enterrados en sus cementerios cercanos o cuando no pudieron hacerlo acondicionaron los lugares en donde los cadáveres fueron encontrados y son los lugares en donde realizan sus rituales funerarios. En los años que venimos buscando y recuperando esos restos humanos y elementos asociados de personas muertas durante los años 1980 al 2000 hemos tenido la oportunidad de llegar a distintos cementerios tanto en 
costa, sierra y selva y registrar diversas practicas funerarias contemporáneas. En ellas hemos podido observar que a pesar del peligro de una inminente agresión por parte de Sendero Luminoso, FFAA y policiales los familiares, amigos y vecinos de los fallecidos trataron de cumplir con sus creencias relacionadas a la muerte. Así hemos visto cadáveres enterrados a muy poca profundidad, en cementerios en donde la fosa debió tener una mayor dimensión, y con las mismas vestimentas que llevaban puesta cuando fueron muertas. Platos, cucharas y botellas les fueron colocados a los cadáveres para que ellos puedan recorrer el largo camino a la muerte. Conocemos poco sobre las costumbres funerarias contemporáneas y de entre ellas desconocemos las prácticas que alteran, inintencionalmente, el contexto funerario de interés forense.

Se presenta tambien en las siguientes lineas informacion oral recolectada durante las labores de campo realizadas en distintas partes del Perú y aquellas escasas informaciones publicadas al respecto.

\section{Ayacucho}

\section{CEMENTERIO DEL DISTRITO DE SANTIAGO DE LUCANAMARCA, PROVINCIA DE HUANCASANCOS}

\section{Compartiendo la última morada: nichos familiares}

El suceso que dio origen a la formación de los contextos funerarios fue la acción que ejerció Sendero Luminoso en abril de 1983. En el año 2002 realizamos la recuperación de 67 individuos esqueletizados depositados en distintos parajes, cementerios lejanos y estancias de puna. De este numero 17 se encontraban enterrados o depositados al interior de nichos en el cementerio del distrito de Santiago de Lucanamarca. De estos contextos los que correspondían a las estructuras en superficie fueron las que proporcionaron un conjunto de prácticas funerarias. Se trata de un cementerio de planta cuadrangular. Los nichos se distribuyen en su mayoría adosados a los muros perimétricos. Una de las cosas que llamo mucha nuestra atención en aquel entonces es que al interior de una estructura funeraria podía encontrarse mas de un individuo ya sea completo o parcialmente completo registrándose en uno de ellos la presencia de un individuo completo rodeado únicamente de cráneos.

Ellos nos permitió plantear cuatro tipos de tratamientos (Estrada 2004):

1. Uso y reuso de la estructura funeraria sin retiro de los restos humanos. Se caracteriza por ser depósitos diacrónicos con alteración de individuos previamente depositados.

2. Uso y reuso de la estructura funeraria con el retiro total de restos humanos y posterior entierro en la entrada del nicho. Se caracteriza por que restos humanos previamente depositados son retirados en su totalidad a excepción de huesos de pies y manos que quedan al fondo del nicho y son los únicos indicadores de un depósito anterior. Tales restos desarticulados son enterrados cerca a la entrada del nicho.

3. Uso y reuso de estructura funeraria con el retiro del esqueleto postcraneal que es enviado al purgatorio y re disposición de los cráneos al interior de la estructura funeraria. Se caracteriza por que se tratan de depósitos diacrónicos de cadáveres con alteración de restos previamente existentes. Al último cadáver depositado se le asocian una serie de cráneos y mandíbulas que son dispuestos a la altura de la cabeza o dispuestos al fondo del nicho.

4. Uso y reuso de estructura funeraria con el retiro total de los restos y su envío al purgatorio. Se caracteriza por que al individuo depositado se le asocian huesos de pies y manos de individuos previamente depositados. 


\section{Nichos con forma de ataúdes antiguos}

Durante las actividades de recuperación de restos humanos en Santiago de Luacanamarca pudimos registrar algunas estructuras funerarias bastantes particulares. Una de ellas, y también la mas común, son los nichos con planta de forma trapezoidal que nos hace recordar la forma de un ataúd antiguo. Estas estructuras están elaboradas con piedras canteadas grandes unidas con argamasa de cemento y enlucido de yeso. Al interior de estas estructuras puede encontrarse más de un individuo.

\section{Nichos subterráneos: Uku nicho}

Durante estas mismas labores tuvimos la oportunidad de registrar dos tipos de estructuras funerarias conocida por pobladores quechuahablantes como Uku Nicho.

El primer tipo de ellos se caracteriza por que a la fosa se le apertura una cavidad anexa dentro de la cual se introduce el cadáver desde la cabeza hasta los hombros. Mientras que el segundo tipo resulta siendo más compleja en su elaboración puesto que a la fosa principal se apertura una cavidad anexa de mayor dimensión dando la apariencia que nos encontramos ante una tumba en forma de bota. A la entrada de esta cavidad anexa se colocó un semicírculo de piedra tallada apoyada en dos cubos del mismo material. El cadáver había sido dispuesto al interior de esta cavidad lateral desde la cabeza hasta las rodillas.

\section{El purgatorio en la tierra: un osario en un cementerio}

El Purgatorio es un pequeño cuarto que se encuentra en el extremo opuesto a la entrada del cementerio de Lucanamarca. A este lugar son enviados los restos humanos provenientes de los nichos cuando el individuo preexistente es retirado total o parcialmente para dar paso a nuevos depósitos de cadáveres al interior de las estructuras funerarias. Los restos humanos dejados aquí a la intemperie sufren un proceso de deterioro que los llevan luego de algunos años a la desintegración de los mismos.

\section{Una escalera para trasladar el cadáver: la chacana}

Uno de los cadáveres depositados en uno de los uku nicho presentaba restos de tejido vegetal a su alrededor dándonos la impresión de que nos encontrábamos ante los restos de un ataúd rustico. Sin embargo nuestros ayudantes de campo, quechuahablantes de la zona, nos indicaron que antiguamente los cadáveres eran trasladados poniéndoles un tronco a cada lado. Este artefacto es conocido como Chacana y es un rustico elemento al cual es atado el cadáver cuando este se encuentra envuelto con frazadas o ponchos. Según nuestros hallazgos realizados la chacana también es depositado conjuntamente con el cadáver.

\section{JuNín}

\section{CEMENTERIO DE CIDRUYO, DISTRITO DE ANDAMARCA, PROVINCIA DE CONCEPCION}

\section{Animales para la otra vida?: restos de animales asociados a un individuo subadulto}

En marzo de 1990 tres personas entre ellos un niño de 4 años desaparecieron en el centro poblado de Cidruyo. Informaciones posteriores brindadas a los familiares por algunos pobladores les señalaban que ellos habían sido muertos por algunos ronderos de Andamarca (un poblado cercano) y Cidruyo y que los adultos habían sido enterrados en una fosa clandestina mientras que el niño había sido enterrado en una de las esquinas del cementerio. Adicionalmente la información recolectada señala que el niño no fue muerto inmediatamente con los padres sino que su muerte se produjo varios días después tiempo durante el cual debió estar bajo la custodia de algún personal. En el año 2005 la excavación 
arqueológica forense realizada nos permitió recolectar los restos óseos de un perro joven, de un cerdo joven y de un ave de especie no identificada que habían sido colocadas encima del cadáver del niño. El individuo subadulto se encontraba envuelto por un plástico de color azul y asociados a él se encontraban una flauta elaborada con un tubo pvc de agua y un maletín deportivo sintético.

\section{HUÁNUCO}

\section{CEMENTERIO DEL CENTRO POBLADO DE HUARACILLO, DISTRITO DE PINRA, PROVINCIA DE HUACAYBAMBA}

\section{Una soga para el camino: Quipus para los muertos}

En 2010 durante las labores de excavación y exhumación de restos humanos y elementos asociados en este cementerio notamos que los individuos adultos llevaban puesta una especie de soga bicolor en la cintura a manera de cinturón. A nuestra consulta sobre este elemento poblador y familiar de los fallecidos nos refirieron que este objeto se llama «Quipu». Este Quipu es una soga bicolor (negro y blanco) torcionado que se coloca como cinturón en el cadáver tanto de individuos femeninos, masculinos, adultos como jóvenes. Esta soga sirve como una defensa del «almita» cuando va al infierno y allí se pelea con otras almas. Siempre tiene que ser negro y blanco y torcido a la izquierda (por que es para defensa dicen) contra diablos y fantasmas. Esta se hace de lana de oveja. Las mujeres hilan y los hombres hacen el Quipu. Dicen que la última noche del velorio cruzan las pitas formando siete nudos como «siete misterios» y en cada nudo hacen como dos cruces «para la salvación». Creen que si no le ponen este cinturón el diablo se lleva el alma. Recalcan que con el quipu «se defiende el alma». Pobladores de este lugar señalan que los adultos llevan puesto un traje de bayeta, una especie de hábito con capucha (franciscano?).

\section{Alitas para ir al cielo: Tratamiento funerario de los niños.}

Cuando los niños mueren se le ponen palmas del monte como alitas. Para ello remojan en agua la palma de monte y luego cuando ya se encuentra húmedo lo tejen como alitas que se lo ponen a los niñitos o parvulitos cuando mueren. Este artefacto lo fabrican las comadres y le ponen hábito blanco de tela de tocuyo «que venden en la tienda». Los hombres tejen la palma y cuando está seco se lo ponen al bebe. Dicen que al bebe lo adornan bastante. Le ponen una florecita roja en la cabeza, en canastitas para las mujeres y en anditas para hombres. De las florecitas hace juguetes. Le ponen un mate para que reciba algo en la otra vida (sin embargo en un contexto vimos un tazón rojo de plástico que reemplazaba esta vasija de mate).

\section{ICA}

\section{CEMENTERIO EL CARMEN DEL DISTRITO DE VISTA ALEGRE, PROVINCIA DE NAZCA}

\section{La venganza en tu boca: Una moneda en la cavidad bucal de un cadáver}

En el año 2010 en el Cementerio de Vista Alegre tuvimos la oportunidad de recuperar el cadáver de un individuo femenino adulto joven que presuntamente había sido asesinada por su esposo. Cuando logramos recuperar el cuerpo pudimos comprobar que debido a la aplicación de formol el cadáver se encontraba en buen estado de conservación a pesar de los dos años transcurridos. El cadáver se encontraba en posición decúbito dorsal con la cabeza orientada al sur y los pies al norte. Lleva puesto un largo vestido de una sola pieza. En la mano derecha le fue puesto un rosario de plástico y una cinta bicolor conformada por una banda blanca y otra negra torsionada que continuaba hasta la mano izquierda para luego seguir, paralela, a los miembros inferiores. Ya en la morgue y una vez que fue 
realizada el registro radiográfico de la cabeza se puede apreciar que a nivel de la boca se encuentra un elemento radiopaco de forma circular el cual recuperado durante la necropsia corresponde a una moneda de Un Nuevo Sol acuñado el 2004. Como parte de la investigación forense habíamos tenido la posibilidad de conversar con dos de los familiares de la fallecida uno de los cuales, el tío, nos indico que él había encargado ponerle una moneda en la boca al cadáver de su sobrina.

\section{DISCUSIÓN Y COMENTARIO}

A diferencia de los sitios clandestinos con restos humanos y elementos asociados los cuales se forman por el accionar de los propios perpetradores del crimen, un lugar destinado a que en el se dispongan de los muertos como en un cementerio tiene la ventaja de que en el podemos observar tratamientos deposicionales ya que familiares, vecinos y amigos pueden cumplir con los rituales funerarios propios de una región en el tiempo en el que se desarrollan estas prácticas y que tienen que ver con el tratamiento mortuorio antes, durante y después del depósito del cadáver.

De acuerdo a Duday (1997) es importante puntualizar sobre lo que el denomina gestos funerarios los cuales son:

- Practicas preparatorias o tratamientos presepulcrales del cadáver (antes del depósito).

- Practicas sepulcrales (la estructura funeraria, la posición del individuo y el material funerario).

- Practicas postsepulcrales (reapertura de la tumba, manipulación de las osamentas, reducción, reinhumacion, etc.).

Los arqueólogos podemos ver directamente la segunda y tercera práctica mientras que la primera puede ser inferida en función de las otras dos.

Nos referiremos en primer lugar a los hallazgos realizados en el Cementerio de Lucanamarca. Nos resulta por demás interesante el nombre de purgatorio dado a la construccion que se encuentra al fondo del cementerio. El Purgatorio es aquel espacio a donde van algunas almas a ser purificadas para luego irse al cielo siendo este por lo tanto un lugar de tránsito. Creemos que en el Cementerio de Lucanamarca los nichos son estructuras funerarias en donde los cadáveres son dispuestos transitoriamente puesto que luego de algunos años los restos humanos son retirados total o parcialmente y luego enviados al «Purgatorio». La ausencia de elementos asociados observados en algunos de los contextos funerarios apoyaría este planteamiento.

El tratamiento postdeposicional del individuo que se da en el cementerio de Lucanamarca sería contrario a la idea que usualmente tenemos del culto dado a los ancestros que tiene que ver con la conservación de los restos humanos. Al disponer de los restos humanos dentro del Purgatorio se les condena a la destrucción debido a que luego de algunos años los restos humanos se deterioran por la prolongada exposición al medio ambiente. Visto el conjunto de los hallazgos en Santiago de Lucanamarca no permiten plantear que estamos ante un tratamiento postedeposicional sumamente complejo. Vergara (1997) señala que en el cementerio de Huamanga se realiza el ritual del Tullu Pallay en donde se recolectan restos óseos de muertos anónimos o de los restos de tumbas olvidadas, el ritual que se desarrolla en el cementerio de Lucanamarca es notablemente distinto ya que este retiro total o parcial de restos se realiza en individuos que no son desconocidos ya que tienen familiares, vecinos o amigos quienes recuerdan la identidad de los mismos. Más aun este retiro total/parcial de los restos de los individuos es realizado con conocimiento directo de los familiares.

Otra de las cosas más notables de algunos de los contextos funerarios observados en Lucanamarca es que al último individuo se le asocian varios cráneos de individuos a los cuales se les retiró el esqueleto postcraneal y son enviados al purgatorio. Es claro que la disposición de los cráneos aislados junto al último cadáver en ser depositado al interior del nicho demuestra intencionalidad. En Ayacucho hemos tenido la oportunidad de ver familias que retiran los cráneos de sus familiares y los llevan a la casa familiar otras veces poseen cráneos a los cuales les prenden velas ya que según la creencia sirven 
como guardianes e impiden la entrada de ladrones a la casa. Finalmente quisiéramos referirnos a la «Chacana» del cual podemos señalar que este artefacto también fue usado en un antiguo cementerio donde hoy se encuentra asentado el Campamento Quichuas en el distrito de Colcabamba, provincia de Tayacaja, departamento de Huancavelica perteneciente la Central Hidroeléctrica del Mantaro. Este contexto funerario presentaba asociaciones con cerámica vidriada. De acuerdo a Uceda (2004) este artefacto también fue usado por la esposa de Juan Argumedo (guía de los periodistas muertos en Uchuraccay en 1983) para trasladar el cadáver. Una fotografía de este objeto puede ser observado en la página 215 del Tomo XVIII de Historia de la Republica del Perú (Palacios 2006).

Otros de los contextos funerarios que llamo mucho nuestra atención fue aquel del Cementerio de Cidruyo. Es evidente que este individuo subadulto recibió un trato diferente ya que mientras que los padres fueron enterrados en una fosa clandestina, que no pudimos ubicar, los restos del niño se encontraban en el cementerio del pueblo lugar de donde fueron recuperados. Nuestra experiencia de estos años nos ha enseñado que los restos humanos de individuos subadultos tienen un trato diferente al de los restos de individuos adultos. Ahora bien que pueden significar los animales dentro de este contexto funerario?. Espejo (s/f) señala que en Huancavelica se hace la recomendación de que «se debe matar al perrito que mas acompañaba al difunto, pues este animalito le llevara agua en la oreja, y le defenderá de los demás animales» (Espejo s/f PP: 35-36), adicionalmente Negro (1995) señala en base a las informaciones de Arriaga que se sacrificaban perros negros para que ayudasen al alma a cruzar el rio. En Atacama, Chile, ocurre algo similar ya que también se mataba al perro, al cual previamente se le había dado de comer, cuando ya iba a ocurrir el entierro del difunto para que le acompañe en el viaje [Fuente: < http://pci.tradicionesdeatacama.cl/creencias/funebres/cuerpo>]. Sin embargo no dejamos de lado la perspectiva forense y dado que se trata de un crimen y que los cadáveres fueron enterrados por los victimarios es posible que los restos de animales hayan sido colocados intencionalmente para confundir y dificultar el hallazgo de los restos humanos del niño.

En la provincia de Nasca se encuentra el Cementerio de Vista Alegre en el cual dos elementos son interesantes: una moneda colocada en la boca del cadáver y una cinta bicolor que parte de una mano y de dirige a uno de los pies del lado opuesto. Cuando conversamos con dos de los familiares presentes durante la labores de recuperación de los restos humanos y elementos asociados nos refirieron que en el caso de la cinta torcida esta debe ir colocada desde la mano derecha hasta el pie izquierdo y tiene como objetivo que la persona que mato a su familiar «no esté tranquila en ningún momento» o «para que le remuerda la conciencia». Por su parte el familiar masculino, tío de la fallecida, señala que él fue quien proporciono la moneda para que le fuera colocada en la boca del cadáver. Señala así mismo que esta es una costumbre que se practica en Puno, lugar en donde laboro durante varios años, y se lo hacen a los cadáveres de personas que mueren de manera violenta para que sus agresores «tengan remordimiento $y$ no vivan en paz».

Finalmente queremos referirnos a los hallazgos de «quipus funerarios» realizados en el Cementerio de Huaracillo. Quipu significa «nudo» lo que indica solo una relación de forma mas no de fondo ya que los quipus prehispánicos eran en su mayoría, o por lo menos los más estudiados, instrumentos que mediante una combinación de cantidad de nudos y colores permitían la contabilización de diversos elementos.

Queremos plantear aquí argumentos que nos permitan alejarlo del concepto de quipu prehispánico y acercarnos al denominado cinturón o cordón de San Francisco. El cordón de San Francisco tiene de tres a cinco nudos. Cuando tienen tres nudos representan: pobreza, obediencia y castidad, cuando tiene cinco nudos estos representan las lesiones o estigmas de Jesucristo: uno en cada mano, uno en cada pie y el último en el costado derecho. En algunos cementerios de Ayacucho hemos tenido la oportunidad de ver esqueletos llevando puesto el llamado habito de San Francisco el cual consiste de una túnica, a veces con capucha, de color marrón y llevan puesto a nivel de la cintura ese cinturón con los mencionados nudos. Adicionalmente podemos señalar que un cadáver recuperado en el cemente- 
rio General de la ciudad de Huánuco presentaba también una soga gruesa atada a la cintura a manera de cinturón dejando dos tirantes paralelos. Esta soga era de un solo color. En esta oportunidad no pudimos recolectar información sobre el significado de tales elementos.

Ruiz Estrada (1998) señala la existencia de quipus funerarios en la comunidad de Cuspon en la provincia de Bolognesi, departamento de Ancash. Por su parte Espejo (s/f), en base a su trabajo etnográfico en Huancavelica, señala que el alma del difunto recorre un largo trecho durante el cual es atacado por perros y gatos por lo que se recomienda que al fallecido se le ate un cordón en la cintura. Con este instrumento se defenderá de los animales que lo ataquen sirviéndole al mismo tiempo para cruzar los abismos. Este investigador no señala si este cordón tiene nudos o no.

Una información muy interesante proviene nuevamente de Atacama, Chile, en donde se tiene referencias de que el Cíngulo ${ }^{1}$ (cinturón) le es colocado al cadáver a manera de cinturón y que esta tiene color blanco y negro y con los hilos torcionada a la izquierda. También se le ponía al cadáver una bata blanca. Señala que el cíngulo tiene la función de borrar las huellas del fallecido que haya dejado en el mundo. Este elemento ayuda al difunto a cruzar al otro lado del rio tirándolo por un extremo y sujetándose del otro para poder cruzarlo [Fuente: <http://pci.tradicionesdeatacama.cl/creencias/ funebres/cuerpo>].

Sin embargo hay dos características de estos «quipus funerarios» que podrían estar relacionados a creencias prehispánicas: la torsión a la izquierda de los hilos, una característica que Arellano (2011) atribuye al culto andino y el hecho de que la soga este conformada por dos hilos de colores: blanco y negro.

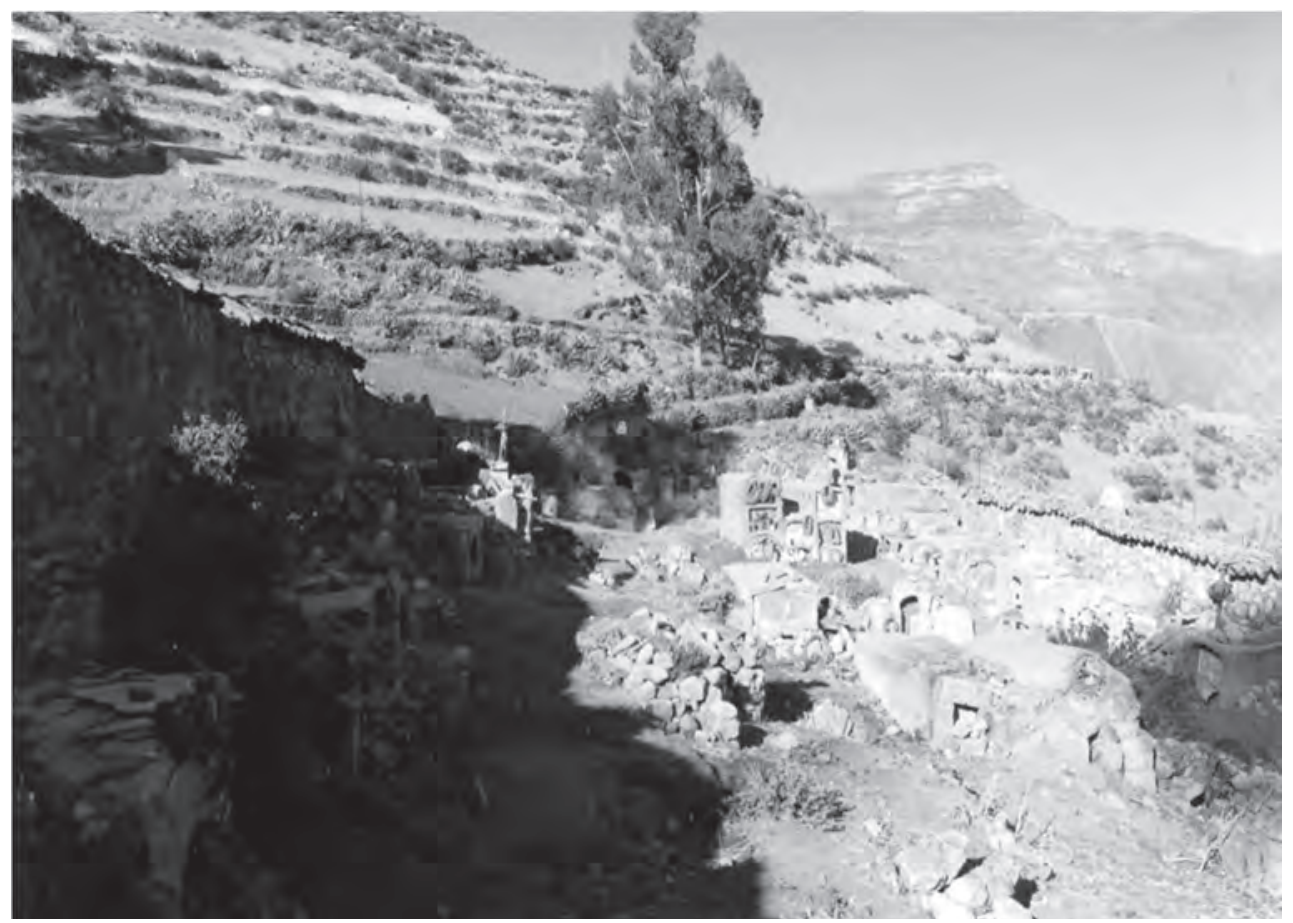

Figura 1. Cementerio de Lucanamarca. Al fondo se observa el osario conocido como «Purgatorio». Esta se se encuentra en el muro opuesto a la entrada del cementerio.

1 Del latín cingulum, cinturón. Es cuerda o cordón con la que se ajusta el alba a la altura de la cintura. En: <http://es.catholic.net/conocetufe/423/2216/articulo.php?id=21383>. 


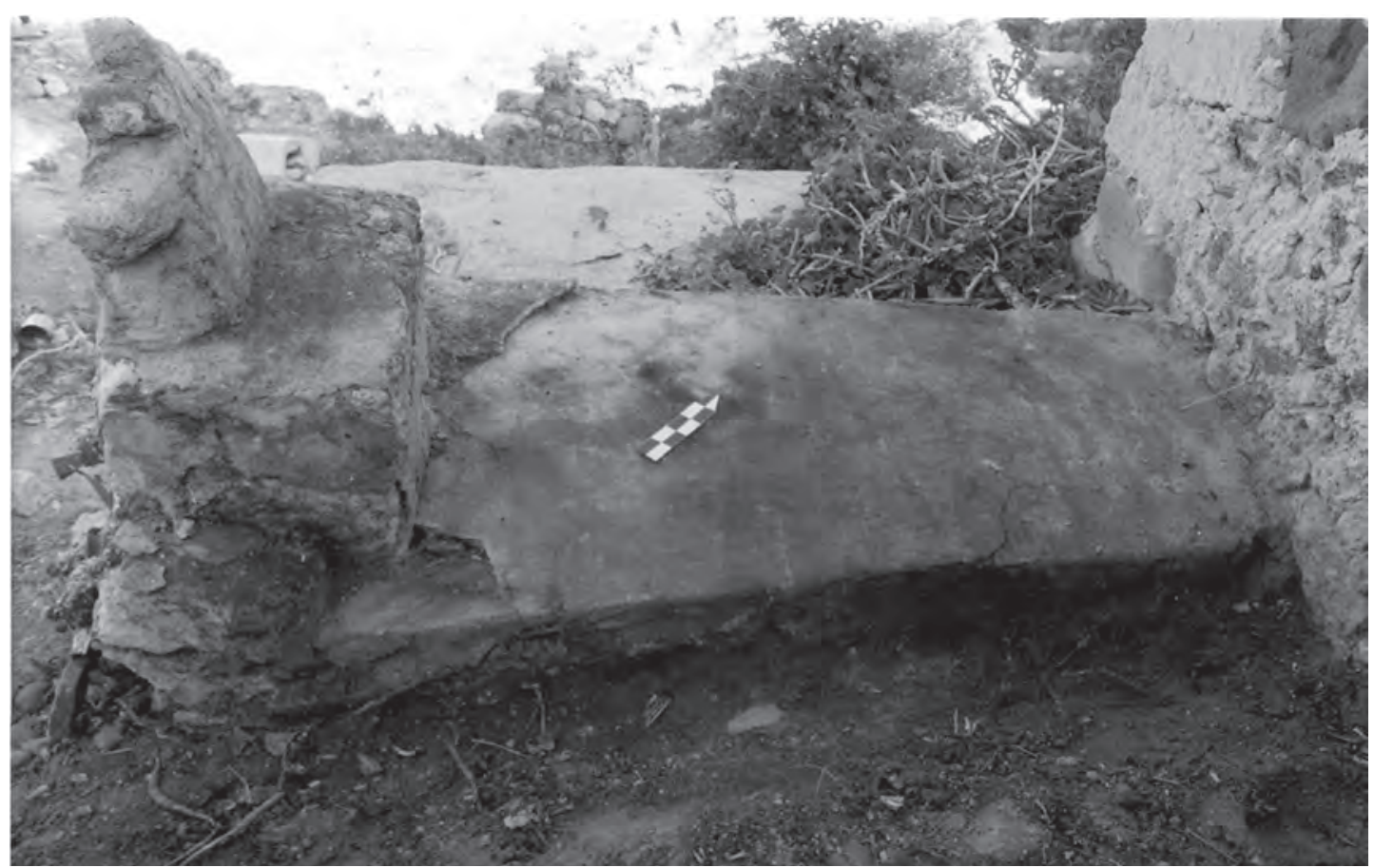

Figura 2. Estructura funeraria con forma trapezoidal que nos recuerda a los ataúdes antiguos.

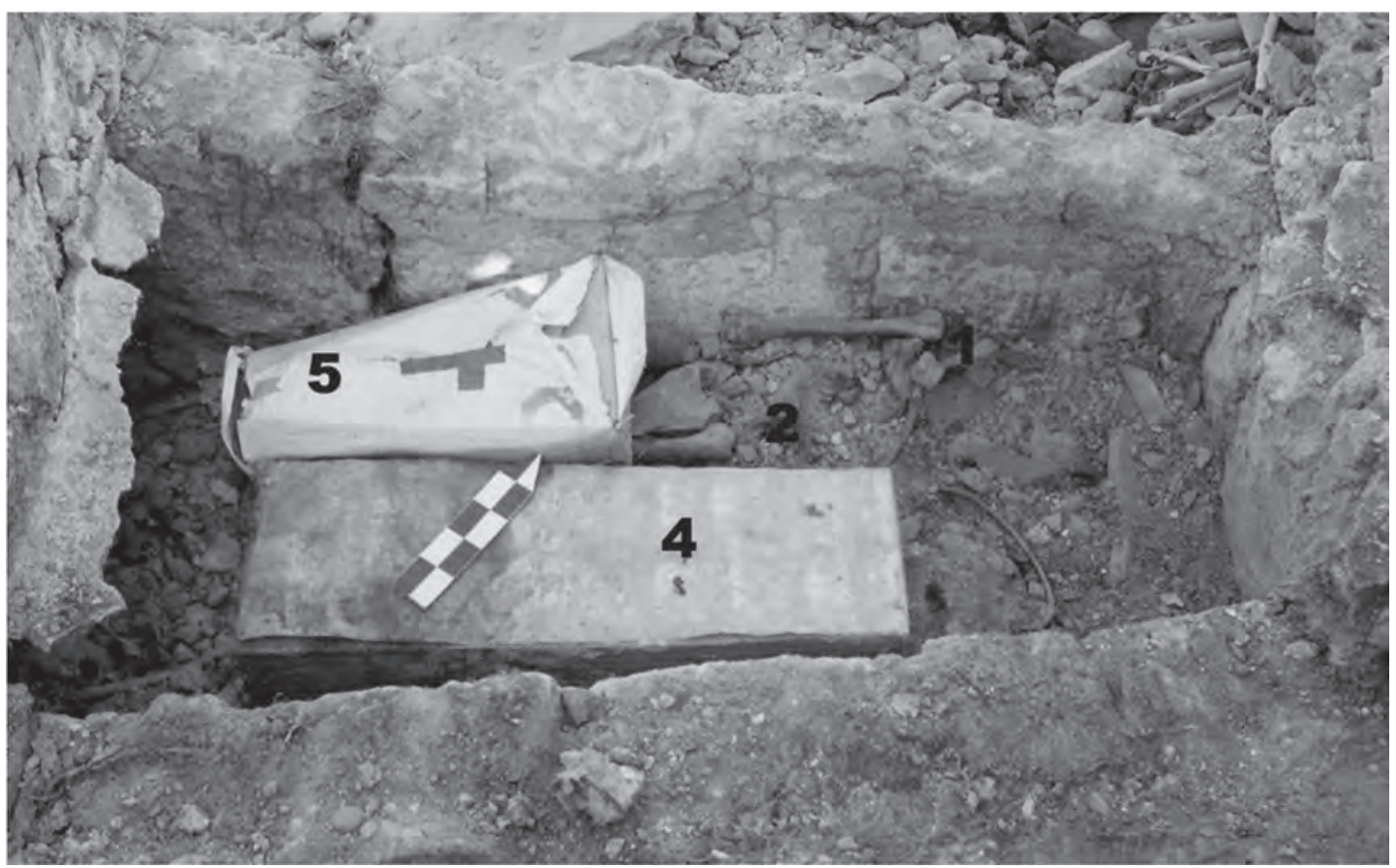

Figura 3. Al interior de la estructura funeraria mostrada anteriormente se encuentran 5 individuos humanos. 3 de ellos son subadultos y 2 adultos. Observar los pequeños ataúdes que también tienen forma trapezoidal que nos recuerdan a los ataúdes antiguos. 


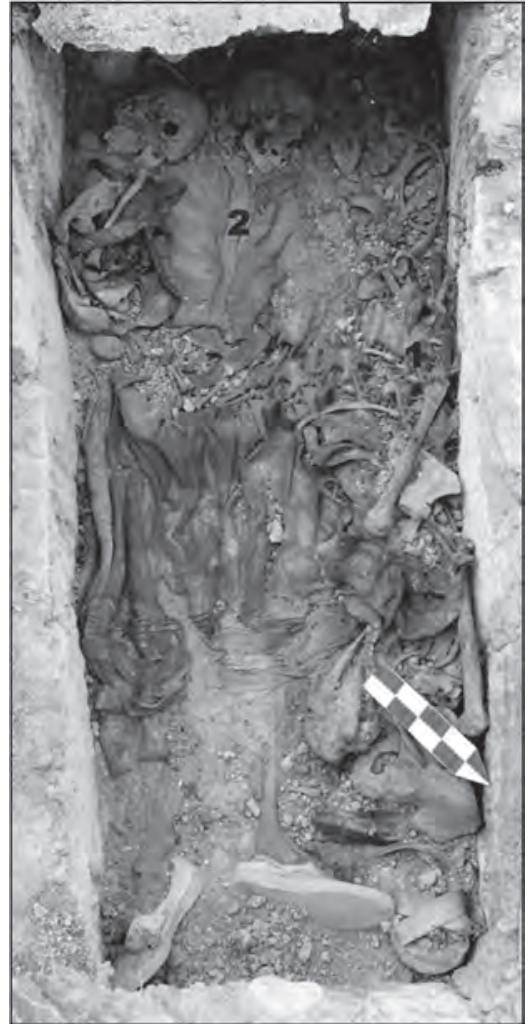

Figura 6. Una vez retiradolos restos del primer individuo depositado al interior de la estructura funeraria se puedeobservar los restos del segundo individuo los cuales corresponden al de una mujer adulta que lleva puesta sus vestimentas y ningún otro elemento asociado.

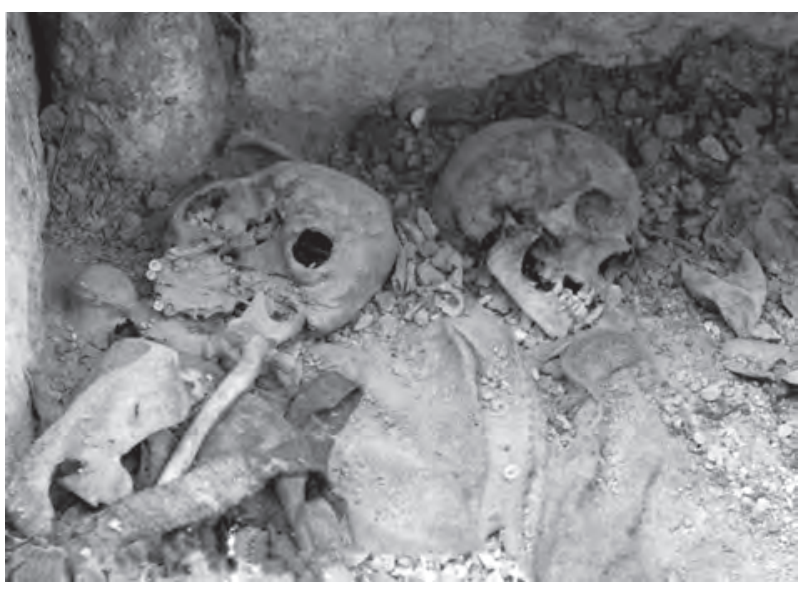

Figura 5. Detalle de los dos cráneos adultos. El cráneo que se encuentra en vista basal fue colocado intencionalmente al lado del cráneo del segundo individuo.

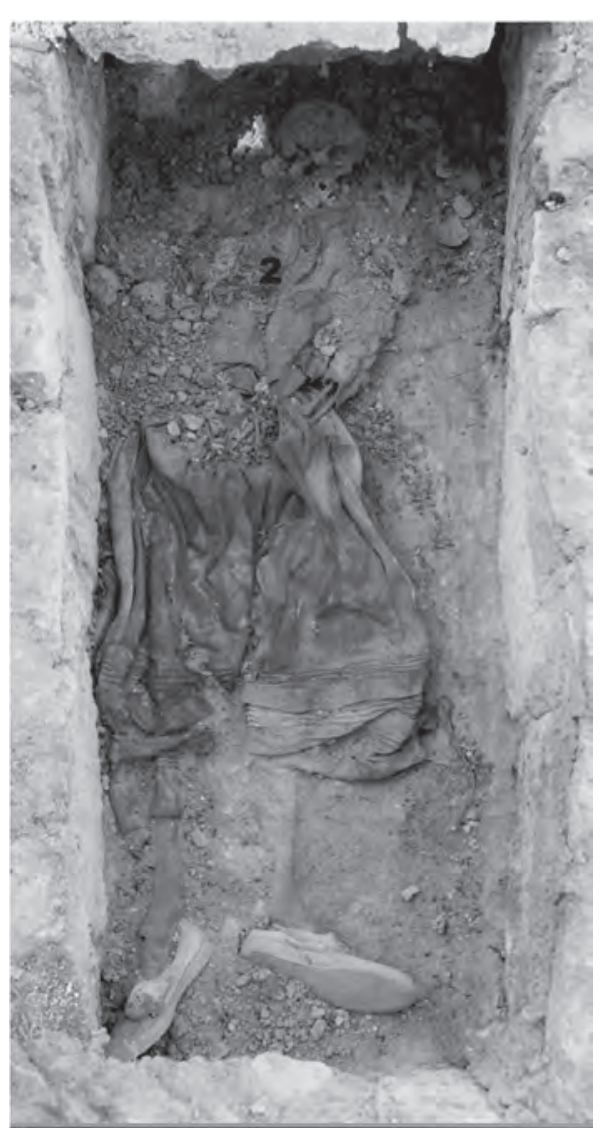

Figura 4. Vista de los dos individuos adultos. Cuando el individuo 2 fue depositado altero los restos previamente dispuesto de otro individuo adulto arrinconándolos hacia el fondo y a un lado de la estructura de ataúd ni tampoco llevan envoltorios ni otros elementos asociados. 


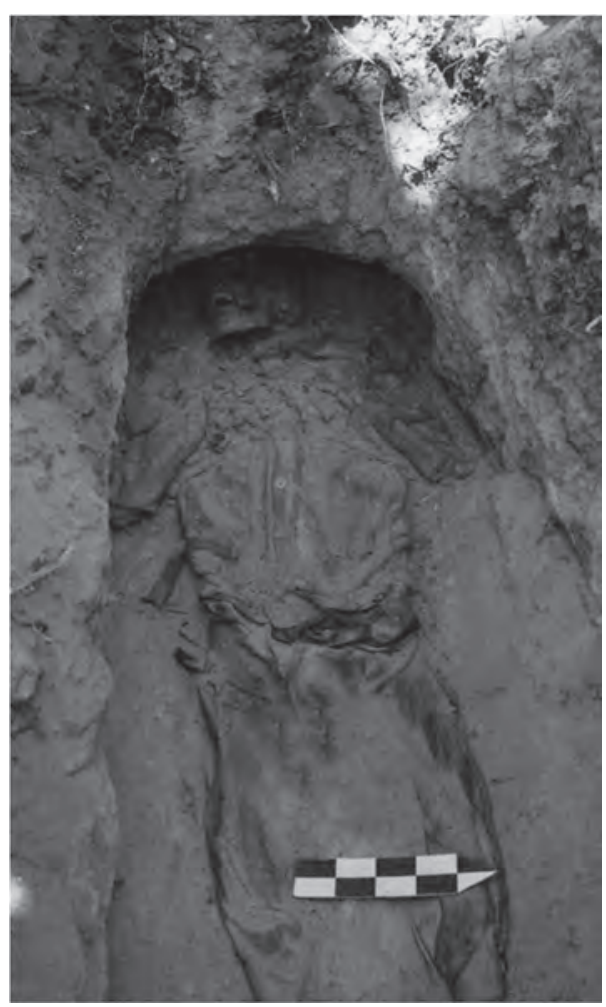

Figura 7 Uku Nicho Tipo I. A la fosa principal se le apertura una cavidad anexa dentro de la cual es colocado el individuo desde la cabeza hasta los hombros.

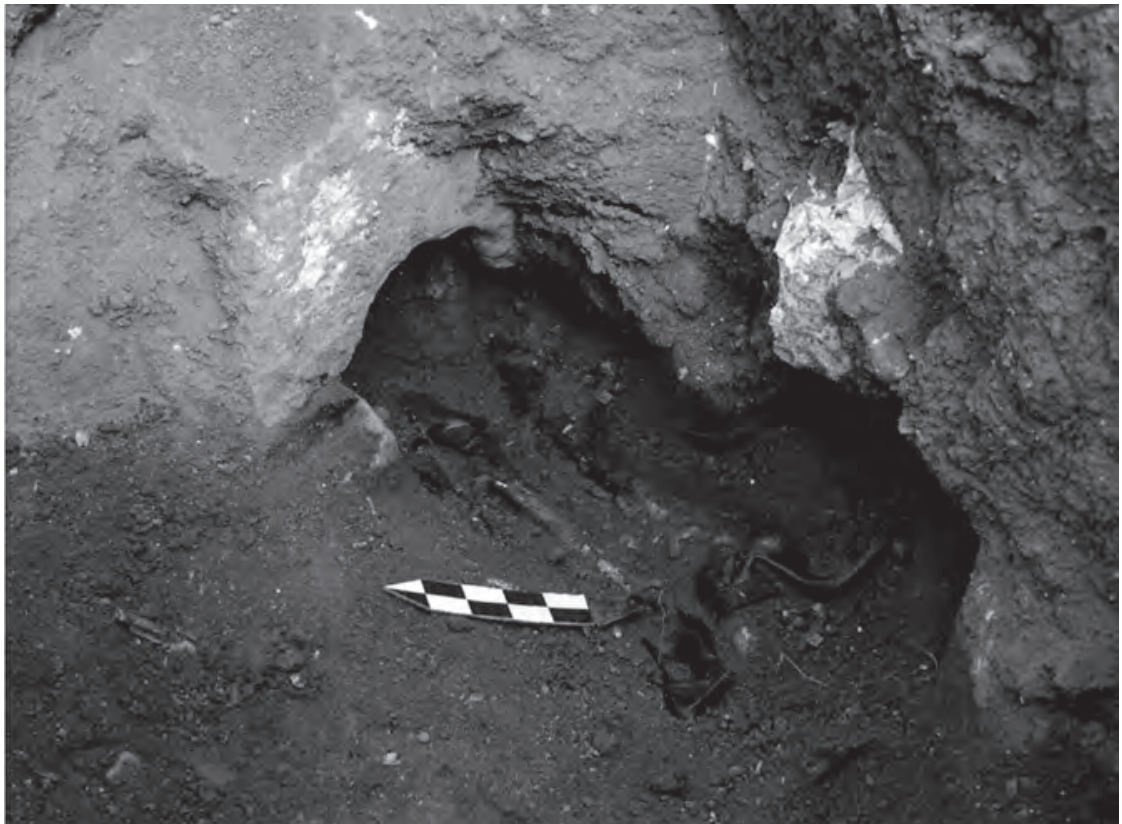

Figura 8. Uku Nicho Tipo II. A la fosa principal se le apertura una cavidad anexa de mayor tamaño en cuya entrada es colocada un semicírculo de piedra tallada. El individuo fue colocado dentro de esta cavidad desde la cabeza hasta las rodillas. 


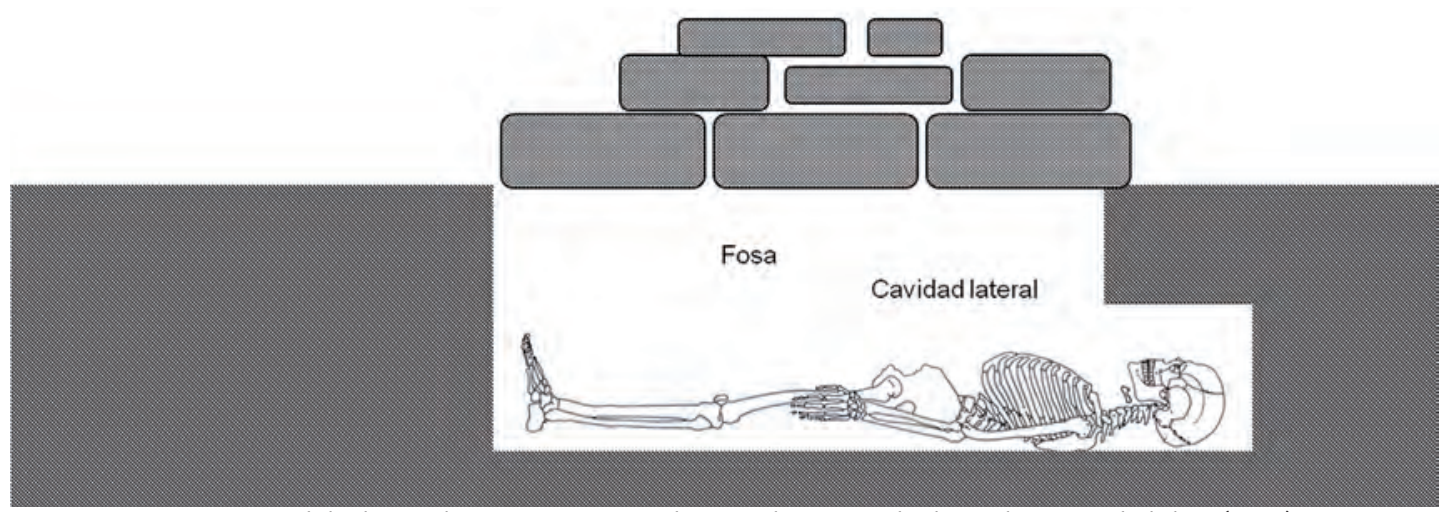

Gráfico 1. Esquema del Uku Nicho Tipo I. Gráfico de esqueleto tomado de Buikstra y Ubelaker (1994).

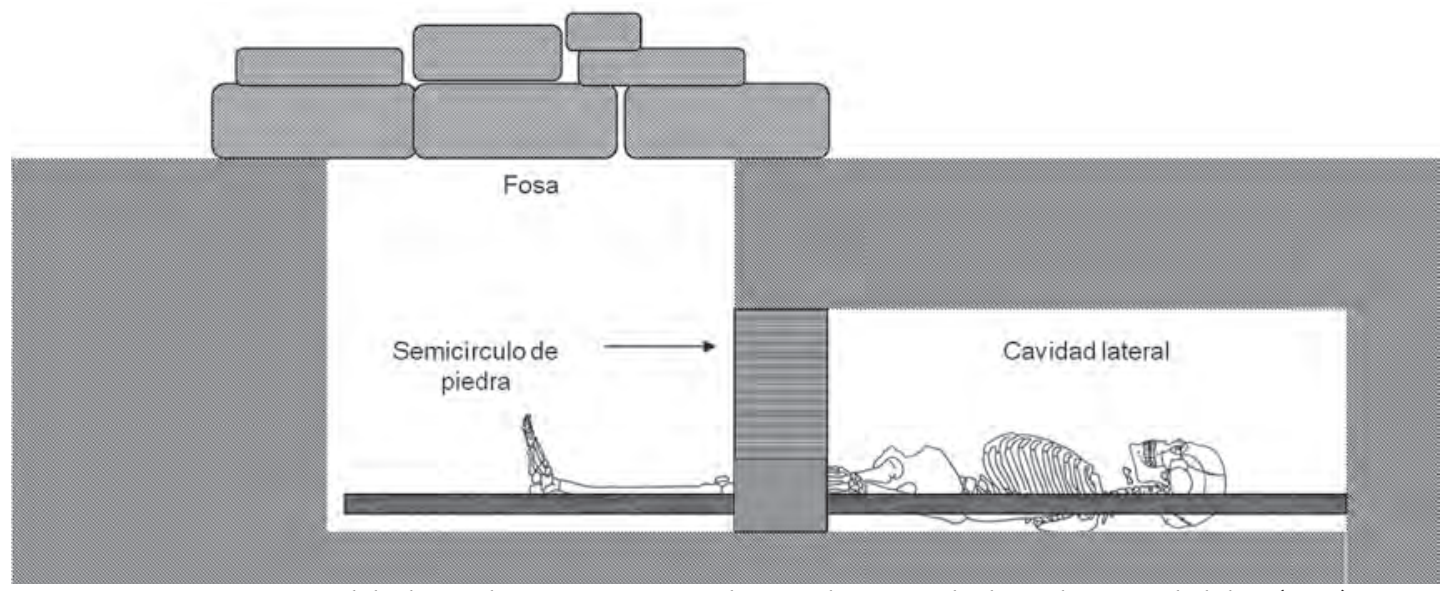

Gráfico 2. Esquema del Uku Nicho Tipo II. Gráfico de esqueleto tomado de Buikstra y Ubelaker (1994).
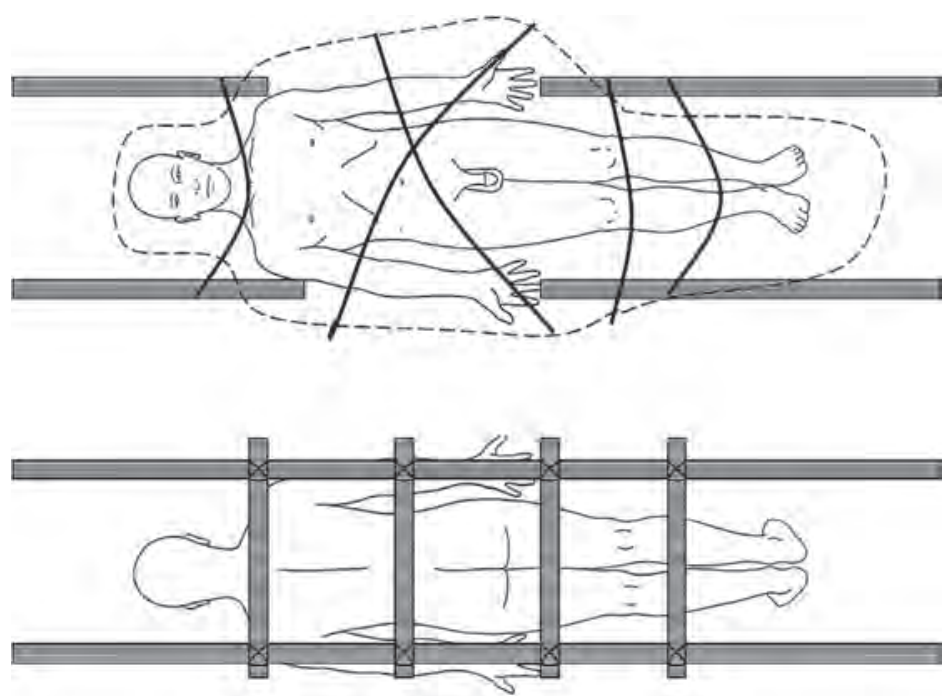

Gráfico 3. Reconstrucción del artefacto conocido como «Chacana» atendiendo a su nombre en quechua. Gráfico de individuo humano tomado de la Defensoría del Pueblo y Equipo Peruano de Antropología Forense (2002). 


\section{BiBLIOGRAFIA}

ARELLANO, Carmen

2011 «El avance en el estudio del quipu: una introducción». En: C.Arellano y G. Urton (eds.) Atando cabos. Museo Nacional de Arqueología, Antropología e Historia del Perú-Ministerio de Cultura. LimaPerú.

ESPEJO, Wilder

s/f Ritos funerarios. Huancavelica. INC. Huancavelica. Perú.

ESTRADA, Flavio

2004 «Notas sobre antiguas practicas funerarias en el distrito de Santiago de Lucanamarca». En: N.Leonardini, D. Rodriguez, V.F.Cabanillas (eds.). Imagen dela Muerte. Primer Congreso Latinoamericano de Ciencias Sociales y Humanidades. UNMSM. Lima-Perú.

BUIKSTRA, Jane y Douglas UBELAKER

1994 Standards. For data collection from human skeletal remains. Arkansas Archaeological Report. Research Series. USA.

\section{DEFENSORÍA DEL PUEBLO Y EQUIPO PERUANO DE ANTROPOLOGÍA FORENSE (EPAF)}

2002 Manual para la investigación eficaz ante el hallazgo de fosas con restos humanos en el Perú. Lima, Perú

DUDAY, Henri

1997 «Antropología biológica «de campo» tafonomía y arqueología de la muerte». En: E. Malvido, G. Pereira, V. Tiesler (Eds.). El cuerpo humano y su tratamiento mortuorio, INHA, Mexico.

UCEDA, Ricardo

2004 Muerte en el Pentagonito. Los cementerios secretos del Ejercito Peruano. Editorial Planeta Colombiana, S.A. Colombia.

NEGRO, Sandra

1995 «La persistencia de visión andina de la muerte en el virreinato del Perú». Ponencia presentada en el Simposio «Las religiones andinas» dentro del Congreso Internacional de Historia de las Religiones, Mexico.

PATRIMONIO CULTURAL INMATERIAL DE SAN PEDRO DE ATACAMA

(Fuente: http://pci.tradicionesdeatacama.cl/creencias/funebres/cuerpo).

PALACIOS, Raúl

2006 Historia de la Republica del Perú (1933-2000).Tomo XVIII. Empresa Editora El Comercio, S.A. Perú.

RUIZ ESTRADA, Arturo

1998 «Los quipus funerarios de Cuspon». Boletín del Museo de Arqueología y Antropología, UNMSM 1, Nº 8. Perú.

VERGARA, César

1997 «Tullu Pallay: ritual de reciprocidad entre la vida y la muerte». En: E. Malvido, G. Pereira, V. Tiesler (eds.). El cuerpo humano y su tratamiento mortuorio, INHA, Mexico. 